\title{
Território e Economia : proposições analíticas
}

\section{Floriano José Godinho de Oliveira}

\section{(e) OpenEdition \\ Journals}

Edição electrónica

URL: http://journals.openedition.org/espacoeconomia/1315

DOI: 10.4000/espacoeconomia.1315

ISSN: 2317-7837

\section{Editora}

Núcleo de Pesquisa Espaço \& Economia

\section{Refêrencia eletrónica}

Floriano José Godinho de Oliveira, «Território e Economia : proposições analíticas », Espaço e

Economia [Online], 5 | 2014, posto online no dia 29 dezembro 2014, consultado o 22 setembro 2020.

URL : http://journals.openedition.org/espacoeconomia/1315; DOI : https://doi.org/10.4000/

espacoeconomia.1315

Este documento foi criado de forma automática no dia 22 setembro 2020.

(c) NUPEE 


\title{
Território e Economia : proposições analíticas
}

\author{
Floriano José Godinho de Oliveira
}

1 Com esta edição, Espaço e Economia: Revista Brasileira de Geografia Econômica entra no terceiro ano de existência e pretende, passado este biênio de experiência, consolidar as relações interdisciplinares na condição de um importante instrumento de debate e proposições analíticas no campo da geografia econômica e da economia regional. Estes são campos do conhecimento que se complementam na análise dos processos de (re) produção das relações sociais de produção que resultam na produção do espaço social (LEFEBVRE, 1976).

2 As interseções teóricas e os estudos nesses dois campos têm sido debatidos em eventos e livros que aprofundam os elementos comuns e, em todas as oportunidades, o território se destaca como a categoria sobre a qual os debates se desenvolvem. Torna-se mais evidente nos dias de hoje o caráter interdisciplinar da geografia, em especial no campo da geografia econômica, e o território como uma categoria cada vez mais presente nos estudos. É, portanto, oportuno intensificarmos o debate sobre a interdisciplinaridade do conceito.

O geógrafo Milton Santos (1996), seguindo os passos do geógrafo americano Edward Soja (1989) e do filósofo francês Henri Lefebvre (1976), realizou uma importante análise sobre os efeitos do processo de reestruturação produtiva no território e propôs uma revisão do conceito, destacando que "é o uso do território, e não o território em si mesmo, que faz dele um objeto de analise social". Santos chamou a atenção para a necessidade de uma "revisão histórica" do conceito, "herdada da modernidade incompleta e do seu legado de conceitos puros, tantas vezes atravessando séculos praticamente intocados" (SANTOS, 1996, p. 15). Segundo o autor, em se "tratando de território, não basta falar de mundialização ou globalização, se desejamos aprofundar o processo de conhecimento desse aspecto da realidade total" (SANTOS, 1996, p. 16).

4 Com esta perspectiva de análise, Santos enfatiza que na atualidade o papel da ciência, da tecnologia e da informação produz novos recortes territoriais, que é resultado "da nova construção do espaço e do novo funcionamento do território" (SANTOS, 1996, p. 16). 
Concretamente, a proposição analítica de Santos afirma que é preciso redefinir nossos parâmetros analíticos para melhor compreendermos as múltiplas determinações econômicas e sociais presentes no espaço social.

5 No campo da economia, autores com forte influência nos debates sobre desenvolvimento e planejamento tem destacado a relação entre desenvolvimento econômico e território. Dois textos se tornaram referências nesta discussão e mostraram a pertinência do que Milton Santos propunha; ou seja, a revisão teórica do conceito e delineamento de novas abordagens. No livro «Economia e Território » (Belo Horizonte - MG : Editora da UFMG, 2005), organizado por Clélio Campolina Dinis (engenheiro e economista) e Mauro Borges Lemos (economista), é destacado logo na apresentação o fato de que o território, mais afeito aos estudos geográficos, foi esquecido no campo da economia regional nas últimas décadas do século XX, mas que é impossível seguir sem reconsiderar uma reapropriação do conceito. Para os autores, há que se rever as metodologias de análise, posto que a compreensão do território é hoje um tema imprescindível, científica e academicamente, bem como social e politicamente, em uma economia globalizada (DINIZ e LEMOS, 2005). Nesse campo de análise, em que o território é reconhecido como espaço social (LEMOS, SANTOS e CROCCO , 2005, p. 175), são retomados antigos referenciais utilizados pelos estudos de economia regional, que focam os processos econômicos e político-institucionais como referência de sua constituição. 0 próprio conceito de território é apresentado pelos autores - ainda que com ênfase nas relações econômicas - em uma perspectiva que vai bem além de suas dimensões e delineamentos físicos. Para Lemos, Santos e Crocco (2006, p. 175), o território é

"[...] o espaço econômico socialmente construído, dotado não apenas dos recursos naturais de sua geografia física, mas também da história construída pelos homens que nele habitam, através de convenções e valores e regras, de arranjos institucionais que lhe dão expressão e formas sociais de organização da produção, com estruturas de poder e dominação. Como espaço social, o território é um campo de forças políticas conflituosas, com estrutura de poder e dominação. Assim, o território é o lócus de produção de bens e reprodução de capital, que se manifesta em arranjos institucionais do poder instituído, embora mutante, que abriga conflitos de interesses e formas de ação coletiva e de coordenação".

$6 \mathrm{Na}$ análise dos autores, no atual estágio de reorganização espacial dos empreendimentos capitalistas, o papel renovado do território expressa as estratégias e novos referenciais locacionais face aos novos processos produtivos.

7 No mesmo sentido e com perspectiva analítica mais voltada ao desenvolvimento regional, o economista Carlão Brandão, em seu livro « Território \& desenvolvimento: as múltiplas escalas entre o local e o global»(Campinas: Editora Unicamp, 2007), demostra que o direcionamento das estratégias dos capitais corporativos para uma escala que denominou local, fez ressurgir a temática territorial. Para Brandão (2007), o território deixou de ser apenas tema dos ambientes acadêmicos e "seus princípios teóricos e ideológicos ", mas " passaram a informar práticas e intervenções discursivas e de ação pública".

8 Contudo, a reapropriação - ou "reassunção de sua merecida posição teórica e política", como assinala Brandão - do conceito de território nas políticas públicas ocorre sem a devida revisão teórica conceitual, como assinalava Milton Santos. 0 território continua sendo visto apenas como a delimitação de um espaço sobre o qual o capital exercerá seu poder, sem ter em conta as novas possibilidades de enfrentamento possíveis, em face 
dos múltiplos interesses e sujeitos presentes na organização do território, e que se originam em múltiplas escalas : do global ao local, do nacional às escalas regionais, que conjugadas formam as teias sócio-econômicas que influem em sua organização.

9 Esse debate tem muitas outras interfaces, é verdade, o que reforça o caráter interdisciplinar do conceito e da discussão, como os aspectos culturais, sociais, das políticas públicas e educacionais, das comunicações etc, que influem nas dinâmicas sociais no território. Por isso, nosso desafio é abrir a revista a todas as abordagens e contribuições. Assim, espaço social, território e economia serão, nessa fase que se inicia com este número, um novo desafio editorial para ampliarmos nossa contribuição às ciências sociais e, em particular, à geografia econômica.

Os artigos que veremos nessa edição já expressam um pouco essa diversidade. Os textos apresentados foram escritos por arquitetos, cientistas políticos, economistas, engenheiros e geógrafos de diversas instituições e países.

11 O artigo que abre este número, de autoria de Sérgio Martins, da Universidade Federal de Minas Gerais, trata da influência da indústria automobilística na conformação e estabelecimento de novas relações sociais no espaço urbano. Não trata da indústria em si, mas sim "como o epicentro de transformações que atravessaram visceralmente as sociedades e as cidades ao longo do século XX".

12 O texto destaca o papel da indústria automobilística no decorrer do século $\mathrm{XX}$, sobretudo com a instituição do denominado modelo fordista, e desenvolve três eixos analíticos importantes. O primeiro de apresentação da questão do automóvel, suas relações históricas com o desenvolvimento do capitalismo urbano-industrial e seu papel no estabelecimento de um "modelo americano" (estadunidense) de sociedade. Um segundo momento de reflexão direta da relação do automóvel com a cidade e o urbano, quando o autor realiza reflexões sobre o modelo brasileiro de desenvolvimento urbanoindustrial e sua relação com a indústria automobilística - onde também é abordada a metropolização de São Paulo. E num terceiro momento de novas reflexões teóricas sobre a racionalidade, a técnica, o espaço e o urbano, baseado especialmente em Marx e Lefebvre, o autor realiza a crítica final da sociedade e do urbanismo que sustenta sua reprodução.

13 O texto seguinte, apresentado por Tamara Egler, Fabiana Mabel e Lucas Trajano, intitulado "Rede no Rio: dominação e indignação" destaca o conceito de ação como a categoria central na compreensão das práticas sociais, procurando distinguir os dois campos em disputas na delimitação das políticas públicas na cidade do Rio de Janeiro: uma envolve "as redes sociotécnicas que associam corporações internacionais, governo em suas diferentes escalas, capitais privados e que atuam e, defesa de interesses globais; e outras redes sociotécnicas que associam atores organizações não governamentais, instituições de governo, capitais privados e pessoas para atuar em defesa do bem comum".

14 Trata-se de uma importante análise sobre as mudanças em cursos na cidade, com vistas a torná-la uma cidade do território global por meio da instituição de redes sociotécnicas que a prepare para a realização de megaeventos como se este fosse o desejo da população. $O$ texto procura desvendar as contradições presentes nas relações que se estabelecem entre política e economia no território para encontrar em sua análise a compreensão associada à enunciação política do discurso até a valorização imobiliária. Por outro lado, mostra o uso das redes sociotécnicas pelos movimentos e 
sujeitos sociais que se organizam para delinear um campo de conflito com uso dessas redes.

A seguir, tendo por base os resultados de pesquisa sobre formas de referenciamento territorial de programas sociais vinculados à escolarização, no Brasil, o artigo de Eveline Algebaile, Gustavo Silva e Tacílio Fagundes discute as mudanças em curso na organização da atuação social do Estado, chamando atenção para as funções que a conjugação entre universalização e focalização territorial parecem cumprir na reorganização da política social brasileira. Lembrando que a distritalização da ação estatal, relacionada à perspectiva universalista, persiste na organização de algumas políticas, os autores apresentam evidências de que esse padrão tem sido cada vez mais substituído ou complementado por um padrão de ação estatal definido pela delimitação de áreas de atuação prioritária. Apresentando a recomposição do campo da educação escolar como um exemplo relevante dessa tendência, discutem as implicações disto em termos de reconfiguração de direitos sociais e de condições para seu exercício.

Os dois artigos que seguem tratam de mudanças na economia regional no território do estado do Rio de Janeiro. O texto de Romeu e Silva Neto e Maria das Dores Rocha destaca a recuperação da economia no território fluminense a partir dos grandes investimentos e das atividades petrolíferas ocorridas, incialmente, nas regiões do interior do estado. Contudo, os autores mostram que em meados da década de 2000 os investimentos passam também a atingir o espaço metropolitano, conjugando um crescimento simultâneo no interior e na metrópole expandida.

mostram que passa a ocorrer uma maior diversificação dos setores produtivos e que cresce a quantidade de grandes projetos de investimentos que impactam, dentre outras coisas, o mercado de trabalho no estado. Metodologicamente, o estudo busca identificar a mudança de trajetória por meio da análise da evolução do estoque de empregos formais nos municípios e regiões do ERJ, onde se busca identificar correlações entre as dinâmicas dos estoques de empregos com os investimentos previstos e em desenvolvimento.

18 O segundo trabalho nesse eixo é o de Thiago Baptista, intitulado "Novos agentes na reconfiguração econômica do território fluminense no início do século XXI: os investimentos chineses no estado do Rio de Janeiro". Neste artigo, o autor enfatiza um aspecto relevante na ampliação dos investimentos econômicos no território fluminense, que é presença dos empreendimentos chineses no Brasil e, em particular, no Rio de Janeiro. Trata-se de texto em que o autor analisa o processo de maior integração funcional das econômicas e dos investimentos produtivos no mundo, resultante da ampliação dos recursos e redes sociotécnicas que se convencionou denominar de globalização. Nesse novo cenário, a economia chinesa passou a ocupar lugar de destaque na economia mundial, tanto pelo fato de ter aberto seu mercado, como por ter ampliado os investimentos produtivos em todo o mundo, tornando uma economia verdadeiramente globalizada. $O$ autor chama atenção para o fato de que no Brasil a maior concentração dos investimentos chineses ocorre no território do estado do Rio de Janeiro. Com isso, esse artigo busca realizar uma análise sobre a distribuição e efeitos espaciais desses investimentos no território fluminense.

Para finalizar a seção de artigos desta edição apresentamos dois importantes ensaios escritos pelo moçambicano Nelson Laura Mabucanhane, mestre em Políticas Públicas pela Peking University, China (2009), e pelo também cientista político polonês Marek Polak, mestre em Relações Internacionais pela Universidade de Varsóvia (2009). 
20 Nelson Laura Mabucanhane nos brinda com um instigante trabalho sobre os possíveis significados econômicos e políticos do quadro de crise dos Estados Unidos da América em seus nexos e tensões com a constituição e fortalecimento da associação entre Brasil, Rússia, Índia, China e África do Sul, na forma de um agrupamento desses mercados emergentes hoje comumente referido pelo termo BRICS. Reportando-se a uma extensa bibliografia sobre o tema, o autor apresenta e discute relevantes aspectos da crise econômica e política dos EUA explicitada a partir do início dos anos 2000, expõe variadas questões formuladas por estudiosos do tema e discute as possibilidades de constituição de uma nova ordem mundial a partir da emergência de novas forças econômicas não completamente alinhadas à hegemonia estadunidense.

21 O trabalho de Marek Polak apresenta um instigante olhar sobre as relações societais nas favelas do Rio de Janeiro, analisando as relações de poder e suas consequências para a formação da personalidade tanto no sentido de grupo, como também no do indivíduo nessas comunidades. $O$ autor realiza uma investigação acerca da instituição dos diferentes poderes que se legitimam no interior das favelas que implicam, cada uma ao seu modo, em novas formas de dominação que isolam o território de relaçães sociais mais intensas com os demais espaços da cidade. $O$ autor trabalha com o conceito de estigma social para caracterizar a forma como é estabelecida a relação dos demais moradores da cidade com os moradores das favelas. Com base nessa interpretação realiza uma análise que procura caracterizar tanto a formação desses territórios de exclusão, quanto às formas de organização dessas comunidades.

Na seção Trilha de Pesquisa, esta edição apresenta dois trabalhos que apontam duas importantes investigações em curso. Hervé Théry, professor convidado na USP, Cátedra Pierre Monbeig, assina o texto "Um gigante do agronegócio em Mato Grosso", em que mostra os traços de um novo cenário na expansão das atividades agropecuárias, em particular a do agronegócio no Brasil. Neste trabalho o autor apresenta as atividades agrícolas no Mato Grosso, identificando a diversificação de culturas e modernização do sistema na região.

23 No âmbito urbano, Gabriel Araújo, da Universidade do Estado do Rio de Janeiro, apresenta um relato de trabalho de campo realizado na área portuária do Rio de janeiro, demonstrando como o território está sendo radicalmente transformado em face do projeto de reurbanização em curso. A investigação procura apontar os interesses econômicos presentes na estruturação do projeto, bem como tenta localizar a origem dos capitais que estão sendo aplicados nos empreendimentos já iniciados.

Encerra esta edição a resenha "Para (re) pensar a América Latina: a vertente descolonial de Walter D. Mignolo", redigida por João Victor Sanches da Matta Machado, estudante de graduação em Relações Internacionais da Universidade Federal Rural do Rio de Janeiro, bolsista PIBIC/CNPQ, sobre o livro "La Idea de América Latina. La herida colonial y la opción decolonial”, de Walter D. Mignolo (Barcelona: Gedisa, 2007 [2005]). A resenha apresenta um dos principais autores da corrente denominada póscolonialista, que realiza uma potente crítica aos interesses imperialistas no continente, debatendo desde o surgimento da palavra América até o seu desenvolvimento como América Latina. 


\section{BIBLIOGRAFIA}

BRANDÃO, Carlos. Território \& desenvolvimento: as múltiplas escalas entre o local e o global. Campinas, Editora Unicamp, 2007.

DINIZ, Clélio Campolina e LEMOS, Mauro Borges (Org). Economia e Território. Belo Horizonte, editora UFMG, 2005.

LEFEBVRE, Henri. El espacio. In. : LEFEBVRE, Henri. Espacio y politica - el derecho a la ciudad II. Barcelona, ediciones península, [1970] 1976, p.23 a 42

MIGNOLO, Walter D. La Idea de América Latina. La herida colonial y la opción decolonial. Barcelona: Gedisa (2007 [2005]). Tradução do original em inglês: Silvia Jawerbaum e Julieta Barba. 241p.

SANTOS, Milton. O retorno do território. In. : SANTOS, Milton ; SOUZA, Maria A. ; SILVEIRA, Maria L. Território - Globalização e Fragmentação. São Paulo, Editora Hucitec, 1996, p.15 a 20.

SOJA, Edward W. Geografias Pós-modernas: a reafirmação do espaço na teoria social crítica. Rio de Janeiro, Jorge Zahar editores, [1989] 1993.

\section{AUTOR}

\section{FLORIANO JOSÉ GODINHO DE OLIVEIRA}

Professor do Programa de Pós-Graduação em Políticas Públicas e Formação Humana (PPFH, Universidade do Estado do Rio de Janeiro. Email: fgodinho@uerj.br. 